\title{
Statins and outcomes in patients admitted to hospital with community acquired pneumonia: population based prospective cohort study
}

\author{
Sumit R Majumdar, Finlay A McAlister, Dean T Eurich, Raj S Padwal, Thomas J Marrie
}

\begin{abstract}
Objectives To determine whether statins reduce mortality or need for admission to intensive care in patients admitted to hospital with community acquired pneumonia; and to assess whether previously reported improvements in sepsis related outcomes were a result of the healthy user effect.

Design Population based prospective cohort study.

Setting Six hospitals in Capital Health, Edmonton, Alberta, Canada.

Participants Adults admitted to hospital with pneumonia and categorised according to use of statins for at least one week before admission and during hospital stay.

Main outcome measures Composite of in-hospital mortality or admission to an intensive care unit.

Results Of 3415 patients with pneumonia admitted to hospital, $624(18 \%)$ died or were admitted to an intensive care unit.

Statin users were less likely to die or be admitted to an intensive care unit than non-users (50/325 (15\%) v 574/3090 (19\%), odds ratio $0.80, \mathrm{P}=0.15$ ). After more complete adjustment for confounding, however, the odds ratios changed from potential benefit (0.78, adjusted for age and sex) to potential harm (1.10, fully adjusted including propensity scores, $95 \%$ confidence interval 0.76 to 1.60 ).

Conclusions Statins are not associated with reduced mortality or need for admission to an intensive care unit in patients with pneumonia; reports of benefit in the setting of sepsis may be a result of confounding.
\end{abstract}

\section{Introduction}

Community acquired pneumonia is a common and costly cause of sepsis. ${ }^{1}$ In the United States pneumonia is the seventh leading cause of death and accounts for about $\$ 9 \mathrm{bn}$ ( $£ 5 \mathrm{bn}$; $€ 7 \mathrm{bn}$ ) in direct costs and 600000 admissions to hospital each year. ${ }^{2-4}$ Case fatality rates of those admitted to hospital are between $8 \%$ and $14 \% \cdot^{2-5}$

Recently, observational studies reported that patients taking 3-hydroxy-3-methylglutaryl coenzyme-A reductase inhibitors (statins) at the time they develop pneumonia or other serious infections are less likely to have sepsis, ${ }^{67}$ die from sepsis, ${ }^{5-11}$ or develop complications necessitating admission to an intensive care unit. ${ }^{11}$ For those admitted with sepsis these benefits range from a $25 \%$ reduction in developing fatal sepsis ${ }^{5}$ to a $30 \%$ reduction in admission to an intensive care unit, ${ }^{11}$ and a $92 \%$ reduction in mortality. ${ }^{9}$ A study restricted to pneumonia reported a significant $64 \%$ reduction in mortality with statin use. ${ }^{5}$ Benefits from statins are not ascribed to cholesterol lowering but rather to pleiotropic effects-antioxidative and anti-inflammatory properties, interference with isoprenoid synthesis resulting in modulation of immunity and reduced cytokine levels, and improvements in endothelial function and thrombomodulation..$^{5-12}$

These pleiotropic effects are also used to explain the findings of numerous observational studies suggesting that statins prevent cancer, ${ }^{13}$ reduce fractures related to osteoporosis, ${ }^{14}$ delay onset and progression of diabetes,,$^{15}$ decrease venous thrombosis, ${ }^{16}$ and prevent dementia. ${ }^{17}$ Given that none of these benefits are apparent in randomised trials of statins, ${ }^{18}{ }^{19}$ an alternative explanation might be that of selection bias and residual confounding.

Specifically, preventive therapy, such as use of statins, is more likely to be prescribed to relatively healthy or health seeking patients ("healthy users") and these patients are also more likely to see their doctor on a regular basis, exercise, eat a healthy diet, stop smoking, be immunised, and adhere to treatments. ${ }^{100-23}$ That is not to say that healthy users do not have comorbidities. For example, consider two 70 year old men discharged from hospital after myocardial infarction. The first patient sees his doctor regularly, stops smoking, loses weight, starts exercising, receives his immunisations, and, after making a request for statins, adheres to treatment. The second patient does not see a doctor, continues to smoke, does not change his diet or lifestyle, and after discharge does not even fill his statin prescription. Administrative databases would consider both to be equivalent 70 year old male survivors of myocardial infarction (code 410, international classification of diseases, ninth edition, clinical modification), but it is apparent that the first patient is a healthy user of statins whereas the other patient is not. Irrespective of statin use it might be surmised that the first patient would have better health related outcomes.

We hypothesised that the benefits of statins in relation to sepsis and community acquired pneumonia are more likely to be a manifestation of the healthy user effect than to the pleiotropic effects of statins. We carried out a large, prospective, population based study of patients admitted to hospital with pneumonia.

\section{Methods}

Details of our study are reported elsewhere. ${ }^{2-4}$ Briefly, from 2000-2 a clinical pathway for community acquired pneumonia ${ }^{24}$ was implemented for adults ( $>17$ years) admitted to all six hospitals in Capital Health, Edmonton, Alberta, Canada. Capital Health is the largest integrated health system in Canada, with an 
annual budget of $\$ 2.2 \mathrm{bn}$, and serves a population of about 1 million people. Over two years 3415 patients with pneumonia were admitted to hospital by 318 doctors. We excluded patients who had tuberculosis or cystic fibrosis, were immunocompromised, or were pregnant.

\section{Data collection, measurements, and exposure}

Six research nurses assisted with implementation of the pathway and prospectively collected data using hospital medical charts, patient or proxy interviews, and standardised abstraction forms. Data included clinical and laboratory findings and information not routinely available in administrative databases, such as functional status, vaccinations for pneumoccocus and influenza, documentation of advanced directives, and drugs used in hospital. We recorded drugs according to class and defined use as drugs taken for at least one week before admission to hospital and continued during hospital stay. We calculated the pneumonia severity index, a validated measure of the severity of pneumonia specific illness at presentation based on three personal variables, five comorbidities, five physical findings, and seven laboratory tests. ${ }^{25}$

The explanatory variable of interest was the use of statins. We did not collect data on specific statins or doses, but simvastatin, pravastatin, and atorvastatin accounted for about $90 \%$ of all statin prescriptions dispensed.

\section{Outcomes}

The primary outcome was the composite of in-hospital mortality or admission to an intensive care unit. This was chosen, a priori, as the best metric to reflect the severity of sepsis as related to community acquired pneumonia. If a patient was admitted to an intensive care unit and died, only the death contributed to the composite outcome. We restricted outcomes to hospital based events. Outcomes were collected prospectively and were ascertained by research nurses blinded to hypotheses regarding statins, healthy user effects, and outcomes.

\section{Statistical analyses}

We carried out a series of multivariate analyses using logistic regression to determine the association between statin use and adverse outcomes. Firstly, we carried out simple adjustment for age and sex. Secondly, we undertook an analysis of a "typical" administrative database and adjusted for age, sex, admission from a nursing home, four comorbidities (ischaemic heart disease, heart failure, chronic obstructive pulmonary disease, neuropsychiatric illnesses), and number of drugs prescribed. Thirdly, we incorporated clinical and laboratory data (for example, the pneumonia severity index) as well as data not routinely available in most administrative databases or chart reviews that might reflect healthy user status (for example, immunisations up to date, functional status, ${ }^{2}$ former smoker ${ }^{26}$ ).

Finally, we included a propensity score for statin use. We used multivariate logistic regression to construct a score that reflected a patient's likelihood of being prescribed a statin (variables available on request). ${ }^{2562728}$ We expected that our propensity score would incorporate variables reflecting healthy user status. We calculated rates of our composite outcome across fifths of increasing propensity and tested for trend using $\chi^{2}$ tests. We then entered the score, as a continuous variable, ${ }^{252728}$ into the models. Finally, we built (without using automated procedures such as forward, backward, or stepwise selection) the best fitting multivariate model of in-hospital mortality or admission to an intensive care unit we could, after forcing in three variables (age, propensity score, statin use) and then including only additional variables that achieved an adjusted $P$ value of less than 0.10 . We
Table 1 Characteristics of 3415 patients admitted to hospital with community acquired pneumonia, stratified by statin use

\begin{tabular}{|c|c|c|c|}
\hline Variables & $\begin{array}{l}\text { No (\%) not using } \\
\text { statins }(\mathrm{n}=3090)\end{array}$ & $\begin{array}{l}\text { No }(\%) \text { using } \\
\text { statins }(n=325)\end{array}$ & $P$ value \\
\hline \multicolumn{4}{|c|}{ Administrative data commonly used for adjustment } \\
\hline Age $\geq 65$ years & $2012(65)$ & $237(73)$ & 0.005 \\
\hline Men & $1621(53)$ & $182(56)$ & 0.22 \\
\hline Admitted from nursing home & $612(20)$ & $25(8)$ & $<0.001$ \\
\hline \multicolumn{4}{|l|}{ Previous condition: } \\
\hline Stroke & $261(8)$ & $45(14)$ & 0.001 \\
\hline Ischaemic heart disease & $751(24)$ & $159(49)$ & $<0.001$ \\
\hline Heart failure & $637(21)$ & $90(28)$ & 0.003 \\
\hline Cancer & $452(15)$ & $37(15)$ & 0.94 \\
\hline Liver disease & $113(4)$ & $4(1)$ & 0.022 \\
\hline Renal disease & $431(14)$ & $59(18)$ & 0.04 \\
\hline $\begin{array}{l}\text { Chronic obstructive } \\
\text { pulmonary disease }\end{array}$ & $944(31)$ & $113(35)$ & 0.12 \\
\hline Neuropsychiatric illness & $644(21)$ & $57(18)$ & 0.16 \\
\hline$\geq 5$ drugs taken & $453(15)$ & $97(30)$ & $<0.001$ \\
\hline \multicolumn{4}{|c|}{ Clinically important data rarely available for adjustment } \\
\hline Former smoker & $983(32)$ & $129(40)$ & $<0.001$ \\
\hline No advanced directive & $2722(88)$ & $318(95)$ & $<0.001$ \\
\hline Pneumococcal vaccine & $669(22)$ & $91(28)$ & 0.009 \\
\hline Influenza vaccine & $793(26)$ & $112(35)$ & 0.001 \\
\hline Independent mobility & $2743(89)$ & $309(95)$ & 0.002 \\
\hline \multicolumn{4}{|c|}{ Pneumonia specific data rarely available for adjustment } \\
\hline \multicolumn{4}{|l|}{ Pneumonia severity index*: } \\
\hline Class I or II & $611(20)$ & $36(11)$ & \\
\hline Class III & $553(18)$ & $87(27)$ & \multirow{3}{*}{$<0.001$} \\
\hline Class IV & $1225(40)$ & $137(42)$ & \\
\hline Class V & $701(23)$ & $65(20)$ & \\
\hline $\begin{array}{l}\text { Levofloxacin not first } \\
\text { antibiotic }\end{array}$ & $958(31)$ & $93(29)$ & 0.38 \\
\hline Aspiration pneumonia & $187(6)$ & $13(4)$ & 0.13 \\
\hline Documented bacteraemia & $183(6)$ & $10(3)$ & 0.035 \\
\hline
\end{tabular}

*Based on three personal variables, five comorbidities, five physical findings, and seven laboratory tests. ${ }^{25}$

report odds ratios with 95\% confidence intervals and $\mathrm{P}$ values. We used the C-statistic as a measure of discrimination that permitted comparisons between models. ${ }^{29}$ By convention a C-statistic greater than 0.8 is considered excellent. ${ }^{29}$ All analyses were carried out using SPSS version 14.

\section{Results}

Overall, 3415 patients (median age 75 years) were admitted to hospital with community acquired pneumonia; $53 \%$ were men, and $10 \%(\mathrm{n}=325)$ used a statin (table 1). Overall, $62 \%$ of the patients $(\mathrm{n}=2128)$ were categorised as high risk groups (class IV or $\mathrm{V}$ ) according to the pneumonia severity index.

Statin users were older and more likely to have atherosclerosis related comorbidities. They still seemed to be healthy users, however, as they were more likely to be admitted from their homes, had independent mobility, were former smokers, were up to date with vaccinations, and had less need for an advanced directive (table 1). These findings were confirmed by the propensity score analysis, which included these variables among others (C-statistic 0.91). Rates of statin use increased across fifths of increasing propensity score: $1 \%, 3 \%, 5 \%, 12 \%$, and $27 \%$ $(\mathrm{P}<0.001$ for trend). Across these same fifths (representing increasing predicted probability of statin use), rates of in-hospital mortality or admission to an intensive care unit progressively decreased: $21 \%, 21 \%, 18 \%, 18 \%$, and $14 \%$ ( $\mathrm{P}=0.003$ for trend).

Overall, $334(10 \%)$ patients died in hospital, $351(10 \%)$ were admitted to an intensive care unit, and 624 (18\%) achieved the 


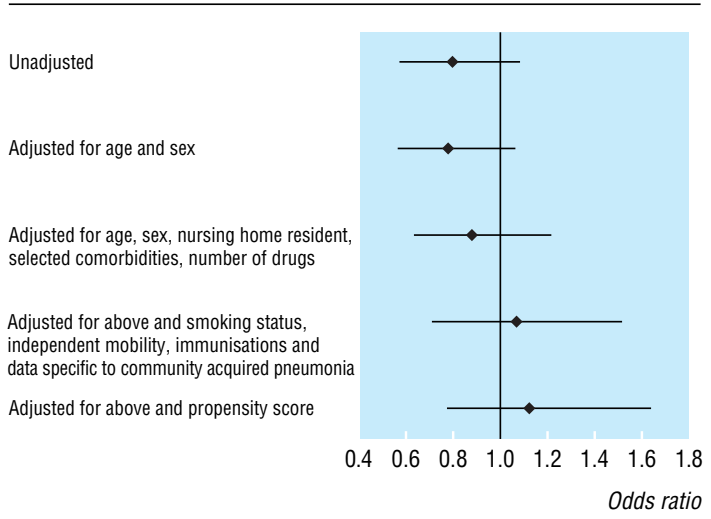

Odds ratios (95\% confidence intervals) for association between statin use and death or admission to an intensive care unit in patients with community acquired pneumonia in models with progressively more complete multivariate adjustment for confounding and comorbidities (ischaemic heart disease, heart failure, chronic obstructive pulmonary disease, and neuropsychiatric illness)

composite end point of death or admission to an intensive care unit. In univariate analyses, patients who used statins were less likely to die than non-users $(25 / 325(8 \%)$ v 309/3090 (10\%), odds ratio $0.75, \mathrm{P}=0.18)$, less likely to be admitted to an intensive care unit $(29 / 325(9 \%)$ v 322/3090 (10\%), odds ratio 0.84 , $\mathrm{P}=0.39$ ), and less likely to achieve the composite outcome of death or admission to an intensive care unit (50/325 (15\%) v $574 / 3090(19 \%)$, odds ratio $0.80, \mathrm{P}=0.15)$. All three univariate analyses suggest a clinically important benefit, and the composite outcome reached marginal statistical significance.

By constructing multivariate models with incrementally greater discriminatory power, the adjusted odds ratio for statin use and adverse outcomes increased from 0.78 (adjusted for age and sex, $95 \%$ confidence interval 0.57 to $1.07, \mathrm{P}=0.12$ ) to 0.88 (typical adjustments in administrative databases including age, sex, nursing home resident, comorbidities, and number of drugs, 0.63 to $1.22, \mathrm{P}=0.43$ ) and to 1.07 (all previous variables plus clinical data, including former smoker, independent mobility, immunisations, and pneumonia severity class, 0.75 to 1.52 , $\mathrm{P}=0.73$; figure). Inclusion of the propensity score as a continuous variable in this last model further moved the estimates in the direction of harm (adjusted odds ratio 1.12, 95\% confidence interval 0.77 to $1.64, \mathrm{P}=0.55$ ). A model including only the propensity score gave an estimate of effect for statin use of 1.01 ( 0.72 to $1.41, \mathrm{P}=0.95)$.

Finally, the best multivariate model of adverse community acquired pneumonia related outcomes was constructed in which only age, propensity score, and statin use was forced. This last model had a C-statistic of 0.84 (table 2); the estimate of statin effect was $1.10(95 \%$ confidence interval 0.76 to $1.60, \mathrm{P}=0.61)$. Models that considered in-hospital mortality only or admission to an intensive care unit only produced virtually identical results with two notable exceptions: older age and heart disease significantly increased risk of mortality (adjusted odds ratio 2.10 and 1.11) but significantly "protected" against admission to an intensive care unit $(0.44$ and 0.21$)$. When these end points were pooled, counter intuitively, older age and heart disease seemed to reduce the risk of adverse events related to community acquired pneumonia (table 2). In no adjusted models, however, did statin use have a statistically significant effect or point estimate consistent with benefit (data not shown).
Table 2 Multivariate logistic regression analysis of correlates for mortality or admission to an intensive care unit in 3415 patients admitted to hospital with community acquired pneumonia

\begin{tabular}{|c|c|c|}
\hline Variables & Adjusted odds ratio $(95 \% \mathrm{Cl})$ & $P$ value \\
\hline Statin use & 1.10 (0.76 to 1.60$)$ & 0.61 \\
\hline Propensity score (continuous) & $0.65(0.22$ to 1.88$)$ & 0.42 \\
\hline \multicolumn{3}{|c|}{ Administrative data commonly used for adjustment } \\
\hline Age $\geq 65$ years & 0.70 (0.54 to 0.91$)$ & 0.008 \\
\hline \multicolumn{3}{|l|}{ Previous condition: } \\
\hline Ischaemic heart disease & $0.70(0.55$ to 0.90$)$ & 0.006 \\
\hline Heart failure & 1.26 (0.99 to 1.61$)$ & 0.056 \\
\hline $\begin{array}{l}\text { Chronic obstructive pulmonary } \\
\text { disease }\end{array}$ & 1.22 (0.98 to 1.53$)$ & 0.077 \\
\hline Neuropsychiatric illness & 1.49 (1.19 to 1.87$)$ & $<0.001$ \\
\hline \multicolumn{3}{|c|}{ Clinically important data rarely available for adjustment } \\
\hline Former smoker & 0.73 (0.57 to 0.93$)$ & 0.010 \\
\hline Pneumococcal vaccine & $0.61(0.40$ to 0.92$)$ & 0.018 \\
\hline Influenza vaccine & 0.43 (0.29 to 0.63$)$ & $<0.001$ \\
\hline Independent mobility & $0.38(0.24$ to 0.58$)$ & $<0.001$ \\
\hline \multicolumn{3}{|c|}{ Pneumonia specific data rarely available for adjustment } \\
\hline \multicolumn{3}{|l|}{ Pneumonia severity index*: } \\
\hline Class I or II & 1.00 & \\
\hline Class III & 2.45 (1.61 to 3.80$)$ & \multirow{3}{*}{$<0.001$} \\
\hline Class IV & 5.13 (3.45 to 7.62$)$ & \\
\hline Class V & 14.40 (9.43 to 22.00$)$ & \\
\hline Levofloxacin not first antibiotic & 2.08 (1.69 to 2.56$)$ & $<0.001$ \\
\hline Aspiration pneumonia & 3.89 (2.74 to 5.53 ) & $<0.001$ \\
\hline Documented bacteraemia & 1.86 (1.29 to 2.67$)$ & 0.001 \\
\hline
\end{tabular}

*See footnote to table 1 .

\section{Discussion}

No association was found between use of statins and mortality or need for admission to an intensive care unit in more than 3000 patients requiring admission to hospital for pneumonia. Although our unadjusted data suggested a 20\% reduction in adverse outcomes among statin users $(\mathrm{P}=0.15)$, with more complete adjustment for confounding our data were more consistent with a $10 \%$ relative increase in adverse outcomes $(\mathrm{P}=0.61)$. Furthermore, our propensity score analyses, which included clinical information not usually available in administrative databases, shows selection bias for those prescribed a statin in the community and probably reflects the healthy user effect. ${ }^{10} 20-2326$

\section{Previous literature}

In a retrospective cohort study from two hospitals that examined community acquired pneumonia related outcomes, Mortensen et al observed a statistically significant $64 \%$ reduction in mortality at 30 days among 110 statin users compared with 677 non-users. ${ }^{5}$ This benefit is more than twice as great as the $28 \%$ reduction in 28 day mortality seen among patients with severe pneumonia treated with activated protein $\mathrm{C}$ in a recent randomised trial. ${ }^{1}$ Although the study by Mortensen et al was carefully carried out, and included a propensity score, it was relatively small, included predominantly men, was retrospective, was not population based, and did not include the types of clinical data we used. ${ }^{5}$ Conversely, the most rigorous "negative" study of statins in relation to sepsis (a population based study with clinical data on 5353 patients admitted to hospital with bacteraemia) also reported no significant association between statin use and 28 day mortality $(\mathrm{P}=0.66$, adjusted $) .{ }^{10}$

\section{Statins as a marker of the healthy user effect}

It seems likely that prescription of statins is a robust proxy for the healthy user effect rather than a measure of the many beneficial pleiotropic effects of these drugs. ${ }^{100-2326}$ Our propensity score 
analyses support this assertion, as do our observations that statin users were more likely to be former smokers and have up to date immunisations for pneumococcus and influenza and less likely to need advanced directives or be admitted from a nursing home. It has been suggested that many of the benefits seen in observational studies of hormone therapy in postmenopausal women (benefits not reproduced in randomised trials) were also a result of this healthy user effect. ${ }^{21}{ }^{22}$ The same gradients in socioeconomic and health status associated with hormone therapy use ${ }^{2122}$ have also been described for statin use..$^{26} 30$ Although the heavily confounded relation between statin use and healthy user status has implications for those studying the effectiveness of statins on atherosclerosis related outcomes, the impact of the healthy user effect might be even more problematic for those searching administrative databases and looking for various non-lipid related benefits of statins. ${ }^{13-17}$

\section{Limitations}

Several limitations merit consideration. Firstly, we examined patients with only pneumonia and cannot make assertions about other serious infections. That said, community acquired pneumonia is common and contributes to many of the patients with sepsis included in previous studies. Secondly, we did not have data on indications, duration of use, doses, or types of statins. Thirdly, we defined statin use as taking statins for at least one week before admission and during hospital stay. Fourthly, our results lack some precision despite the size of our sample, and $95 \%$ confidence intervals are consistent with a $24 \%$ decrease or a $60 \%$ increase in adverse outcomes. Lastly, we examined only admissions to an intensive care unit and mortality during hospital stay; one study has suggested no early benefit from statin use but better late outcomes for those who survive the index episode. ${ }^{10}$

\section{Conclusions}

In our study, patients with pneumonia who used statins did not have better outcomes than non-users. Our analyses raise concerns that previous observational studies that show the benefits of statins in patients with sepsis (and other conditions not related to atherosclerosis) might have been consistently measuring and reporting the healthy user effect. On the basis of our unadjusted data of a $4 \%$ absolute (20\% relative) reduction in death or admission to an intensive care unit, we estimate that at least 3000 patients with pneumonia would need to be randomised to statin or placebo to test the statin hypothesis.

We thank the community acquired pneumonia pathway research nurses JoAnne deJager, Linda Gardner, Lynne Korobanik, Tammy Pfeiffer, Cynthia Proskow, Sue Marshall, and Fredrika Herbert; the staff of EPICORE (University of Alberta) for data management services; and David $\mathrm{S}$ Fedson for discussions and encouragement to pursue this study.

Contributors: All authors conceived and designed the study, interpreted the results, revised the manuscript for important content, and approved the final manuscript. SRM drafted the initial manuscript. TJM acquired the data and obtained funding. SRM is guarantor.

Funding: Supported by an establishment grant from Alberta Heritage Foundation for Medical Research (AHFMR); grants-in-aid from Capital Health; and unrestricted grants from Abbott Canada, Pfizer Canada and Janssen-Ortho Canada. SRM and FAM receive salary support awards from AHFMR and the Canadian Institutes of Health Research. FAM holds the Merck-Frosst Aventis Chair in Patient Health Management. DTE receives a doctoral student fellowship from AHFMR.

Competing interests: None declared.

Ethical approval: This study was approved by the ethics board of the University of Alberta.

1 Laterre PF, Garber G, Levy H, Wunderink R, Kinasewitz GT, Sollet JP, et al. Severe community-acquired pneumonia as a cause of severe sepsis: data from the PROWESS study. Crit Care Med 2005;33:952-61.
2 Marrie TJ, Wu LL. Factors influencing in-hospital mortality in community-acquired pneumonia: a prospective study of patients not initially admitted to the ICU. Chest 2005; $127: 1260-70$

3 McAlister FA, Majumdar SR, Blitz S, Rowe BH, Romney J, Marrie TJ. The relation between hyperglycemia and outcomes in 2471 patients admitted to hospital with community-acquired pneumonia. Diabetes Care 2005;28:810-5.

4 Basi SK, Marrie TJ, Huang JQ, Majumdar SR. Patients admitted to hospital with suspected pneumonia and normal chest radiographs: epidemiology, microbiology, and outcomes. Am J Med 2004;117:305-11.

5 Mortensen EM, Restrepo MI, Anzueto A, Pugh J. The effect of prior statin use on 30-day mortality for patients with community acquired pneumonia. Resp Res 2005;6:1-7.

6 Hackam DG, Mamdani M, Li P, Redelmeier DA. Statins and sepsis in patients with cardiovascular disease: a population-based cohort analysis. Lancet 2006;367:413-8.

7 Fernandez R, De Pedro VJ, Artigas A. Statin therapy prior to ICU admission: protection against infection or a severity marker? Intensive Care Med 2006;32:160-4

8 Liappis AP, Kan VL, Rochester CG, Simon GL. The effect of statins on mortality in patients with bacteremia. Clin Inf Dis 2001;33:1352-7.

Kruger P, Fitzsimmons K, Cook D, Jones M, Nimmo G. Statin therapy is associated with fewer deaths in patients with bacteremia. Intensive Care Med 2006;32:75-9.

10 Thomsen RW, Hundborg HH, Johnsen SP, Pedersen L, Sorensen HT, Schonheyder HC, et al. Statin use and mortality within 180 days after bacteremia: a population based cohort study. Crit Care Med 2006:34:1080-6.

11 Almog Y, Shefer A, Novack V, Maimon N, Barski L, Eizinger M, et al. Prior statin therapy is associated with a decreased rate of severe sepsis. Circulation 2004;110:880-5.

12 Terblanche M, Almog Y, Rosenson RS, Smith TS, Hackam DG. Statins: a panacea for Terblanche M, Almog Y, Rosenson RS,
sepsis? Lancet Infect Dis 2006;6:242-8.

13 Graaf MR, Beiderback AB, Egberts AC, Richel DJ, Guchelaar HJ. The risk of cancer in users of statins. J Clin Oncol 2004;22:2388-94.

14 Wang PS, Solomon DH, Mogun H, Avorn J. HMG-CoA reductase inhibitors and the risk of hip fractures in elderly patients. JAMA 2000;283:3211-6.

15 Padwal R, Majumdar SR, Johnson JA, Varney J, McAlister FA. A systematic review of drug therapy to delay or prevent type-2 diabetes. Diabetes Care 2005;28:736-44.

16 Ray JG, Mamdani M, Tsuyuki RT, Anderson DR, Yeo L, Laupacis A. Use of statins and the subsequent development of deep vein thrombosis. Arch Intern Med 2001;161:140510.

17 Jick H, Zornberg GL, Jick SS, Seshadri S, Drachman DA. Statins and the risk of demenjick H, Zornberg GL, Jick SS,
tia. Lancet 2000;356:1627-31.

18 Heart Protection Study Collaborative Group. MRC/BHF heart protection study of cholesterol lowering with simvastatin in 20536 high-risk individuals: a randomized placebo controlled trial. Lancet 2002;360:7-22.

19 Cholesterol Treatment Trialists' Collaborators. Efficacy and safety of cholesterollowering treatment: meta-analysis of data from 90,506 participants in 14 randomised trials of statins. Lancet 2005;366:1267-78.

20 Ray WA. Evaluating medication effects outside of clinical trials: new-user designs. Am J Epidemiol 2003;158:915-20.

21 Pettiti DB. Hormone replacement therapy and heart disease prevention: experimentation trumps observation. JAMA 1998;280:650-2.

22 Col NF, Pauker SG. The discrepancy between observational studies and randomized trials of menopausal hormone therapy. Ann Intern Med 2003;139:923-9.

23 Simpson SH, Eurich DT, Majumdar SR, Padwal RS, Tsuyuki RT, Varney J, et al. A metaanalysis of the association between drug therapy adherence and mortality. BMJ 2006;332:15-9.

24 Marrie TJ, Lau CY, Wheeler SL, Wong CJ, Vandervoort MK, Feagan BG. A controlled trial of a critical pathway for treatment of community-acquired pneumonia (the CAPITAL study). JAMA 2000;283:749-55.

25 Fine MJ, Auble TE, Yealy DM, Hanusa BH, Singer DE, Coley CM, et al. A prediction rule to identify low-risk patients with community-acquired pneumonia. $N$ Engl J Med 1997;336:243-50.

26 Majumdar SR, Gurwitz JH, Soumerai SB. Undertreatment of hyperlipidemia in the secondary prevention of coronary artery disease. J Gen Intern Med 1999;14:711-7.

\section{What is already known on this topic}

Statins have been reported to prevent sepsis and reduce complications from serious infections such as pneumonia, as well as preventing cancer, fractures, diabetes, and dementia

One explanation for such disparate findings is selection bias and confounding, namely the healthy user effect

\section{What this study adds}

Use of statins in patients admitted for pneumonia did not reduce mortality or need for admission to an intensive care unit

Patients prescribed statins were relatively healthy users

Observational studies showing the putative benefits of statins in patients with sepsis (and perhaps other conditions) were probably reporting confounding by the healthy user effect 
97 Rosenbaum PR, Rubin DB. The central role of the propensity score in the comparison of a treatment to a non-randomized control group. Biometrika 1983;70:41-55.

28 Eurich DT, Majumdar SR, McAlister FA, Tsuyuki RT, Johnson JA. Improved clinical outcomes associated with metformin in patients with diabetes and heart failure. Diabetes Care 2005;28:2345-51

29 Hosmer DW, Lemeshow S. Assessing the fit of a model. In: Applied logistic regression, 1st d. New York: Wiley, 1989:140-5.

30 Thomsen RW, Johnsen SP, Olesen AV, Mortensen JT, Boggild H, Olsen J, et al Socioeconomic gradient in the use of statins among Danish patients: population-based cross-sectional study. Br J Clin Pharmacol 2005;60:534-42.

(Accepted 12 September 2006)

doi $10.1136 /$ bmj.38992.565972.7C
Department of Medicine, Faculty of Medicine and Dentistry, University of Alberta, Edmonton, AB, Canada

Sumit R Majumdar associate professor

Finlay A McAlister associate professor

Dean T Eurich research associate

Raj S Padwal assistant professor

Thomas J Marrie professor

Correspondence to: Dr S R Majumdar, 2E3.07 Walter Mackenzie Health Sciences Centre, University of Alberta, 8440-112th Street, Edmonton, AB, Canada, T6G

2B7me2.majumdar@ualberta.ca 